\title{
The influence of dietary intake on the insulin-like growth factor (IGF) system across three ethnic groups: a population-based study
}

\author{
AH Heald ${ }^{1,2, *}$, JE Cade ${ }^{3,4}$, JK Cruickshank ${ }^{3}$, S Anderson ${ }^{3}$, A White ${ }^{1}$ and JM Gibson ${ }^{1}$ \\ ${ }^{1}$ Endocrine Sciences Research Group, Faculty of Medicine and School of Biological Sciences, \\ University of Manchester, Manchester, UK: ${ }^{2}$ Department of Diabetes and Endocrinology, University of Manchester, \\ Salford Royal Hospitals University Trust, Hope Hospital, Stott Lane, Salford, Greater Manchester M6 8HD, UK: \\ ${ }^{3}$ Clinical Epidemiology Unit, Department of Medicine, University of Manchester, Manchester, UK: \\ ${ }^{4}$ Current address: Nutritional Epidemiology Group, Nuffield Institute for Health, University of Leeds, Leeds, UK
}

Submitted 28 May 2002: Accepted 5 September 2002

\begin{abstract}
Objective: The insulin-like growth factor (IGF) system has been implicated in the aetiopathogenesis of cancer, cardiovascular disease and diabetes. Since dietary factors and ethnicity are considered contributory to the development of these diseases, we examined the IGF system in relation to nutritional intake by ethnic group.

Design, subjects and setting: Dietary intake in 257 subjects of White European, African-Caribbean and Pakistani ethnic origin living in Manchester, UK was assessed using ethnic-group-specific food-frequency questionnaires to assess habitual nutrient intake over the previous 12 months. Fasting IGF-I, IGF-II and IGF-binding protein-1 (IGFBP-1) concentrations were determined and their relationship to specific dietary constituents was analysed.

Results: Analysis by quintiles of nutrient intake showed a significant increase in circulating IGF-I concentration with increasing dietary fat intake ( $F$ for trend $=3.9$, $P<0.01)$, saturated fat intake $(F=3.3, P=0.01)$ and for protein intake $(F=4.2$, $P<0.01)$. There was also a significant increase in IGF-II by quintiles of dietary protein intake $(F=2.7, P<0.05)$. There was a trend for increasing IGF-I with increasing energy intake. The relationships between circulating concentration of IGFBP-1, an acute regulator of IGF action, and fat/protein intake were opposite to those for IGF-I and IGF-II. Multiple linear regression modelling showed that people of Pakistani origin and older subjects had lower levels of IGF-I (Pakistani origin vs. others, $P<0.001$ ) (age, $P<0.001$ for both). There was an independent inverse relationship between IGF-I and dietary carbohydrate intake $(P=0.036)$.

Conclusions: This study provides evidence for a dietary contribution to regulation of the IGF system, although the effects of ethnicity on circulating IGF levels remain dominant. We propose that the IGF system's influences on cancer risk in specific ethnic groups are potentially modifiable by dietary intervention.
\end{abstract}

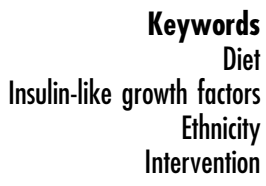

With 35\% of cancer deaths being attributable to dietary components $^{1}$, there has been great interest recently in links between the insulin-like growth factor (IGF) system and cancer ${ }^{2}$. How the IGF system is influenced by diet is uncertain. The IGFs are potent mitogenic factors that play a pivotal role in stimulating cell proliferation and differentiation and inhibiting apoptosis $^{3}$. Raised IGF-I levels have been closely linked with the development of breast and prostate cancer ${ }^{4,5}$ and also colon cancer $^{6}$, whilst low circulating IGF-I levels are implicated in the development of insulin resistance and heart disease ${ }^{7}$. IGF-II has a particularly important role in tumourigenesis and metastasis in several tumour types, particular Wilm's tumour, rhabdomyosarcoma and neuroblastoma ${ }^{8}$.

At least six IGF-binding proteins (IGFBPs) can inhibit or enhance the actions of IGFs. These opposing effects are determined by the structures of the binding proteins and regulated in part by IGFBP proteases ${ }^{3}$. An increased risk of occurrence of solid tumours correlates with raised concentrations of IGF-I and decreased risk with relatively high levels of IGFBP- $3^{9}$.

Since the IGFs, dietary factors and ethnicity are considered contributory to the development of cancer, diabetes and macrovascular disease, we have explored the relative effects of ethnicity and nutrition on the IGF 
system, with the aim of identifying potentially modifiable dietary factors that modulate the IGF system.

\section{Methods}

Subjects were randomly sampled from seven general practice registers in inner city Manchester, UK. Three different ethnic groups were sampled: White European $(n=72)$, Pakistani $(n=76)$ and African-Caribbean origin $(n=109)$. African-Caribbean and Pakistani ethnicity required three out of four grandparents to be classified in that ethnic group, excluding people of direct African origin. Fasting blood samples were taken. Blood samples were centrifuged and aliquots of plasma or serum were frozen at $-70^{\circ} \mathrm{C}$ until analysis. Standardised measures of anthropometry such as body mass index (BMI), calculated as weight in kg divided by the square of height in metres, and waist-to-hip ratio were taken by trained fieldworkers. Ethical permission was granted by the Central Manchester Health District Ethical Committee with written or independently witnessed consent by each subject.

Dietary intake was assessed by an ethnic-group-specific food-frequency questionnaire (FFQ). The FFQ aimed to assess nutrient intake during the previous 12 months and included those foods contributing at least $90 \%$ of total intakes of energy, fat, carbohydrate and protein, as previously described ${ }^{10}$. Where possible, a 24-hour recall was also obtained for subjects from the Pakistani and White European groups and from a subset of the AfricanCaribbean group to act as a cross-check with the FFQ data. The FFQ for the group of White European origin contained 200 food items, for the Pakistani group it contained 162 food items and for the African-Caribbean group it contained 108 food items. Standard portion sizes were assumed for the Pakistani and White European groups based on data collected specifically from the population and published sources ${ }^{11}$. Portion size details were collected in the FFQ for the African-Caribbean group.

Fasting IGF-I, IGF-II and IGFBP-1 concentrations were determined by previously reported, in-house, antibodybased assays ${ }^{12,13}$. Respective detection limits were $28 \mathrm{ng} \mathrm{ml}^{-1}$ (IGF-I), $30 \mathrm{ng} \mathrm{ml}^{-1}$ (IGF-II) and $1 \mathrm{ng} \mathrm{ml}^{-1}$ (IGFBP-1) and within and between coefficients of variation were $<10 \%$. Quality controls of human plasma at known concentrations were included in each assay. All samples were assayed in duplicate. Batching was carried out so that there was a mixture of samples from each ethnic group in each assay.

\section{Statistical analysis}

Statistical analyses were carried out using the statistical package SPSS for Windows, release 7.5 (SPSS Inc., Chicago, IL, USA). Non-normally distributed variables of IGF-I, IGF-II, insulin, protein, fat and carbohydrate were logarithmically transformed prior to analysis. Initial analysis explored circulating IGF levels by quintiles of nutrient intake for the whole group and for each ethnic group separately. Comparison of means was by analysis of variance. For univariate correlations between continuous variables, Pearson correlations were used.

Multiple regression modelling was used to examine the relationships between components of the IGF system and other measured variables.

\section{Results}

\section{Descriptive data}

The mean age of the subjects was 51 years (range 25-78 years). The African-Caribbean males were slightly older at 55 years (95\% confidence interval (CI) 50-59 years) than the Pakistani males (50 years, 95\% CI 46-53 years). Total nutrient intakes were higher in men than in women. European women had a higher percentage of energy from carbohydrate (and starch) than the European men (Table 1). The highest percentage of energy from carbohydrate was in the African-Caribbean group. Carbohydrate in the analysis refers to glycaemic carbohydrates (sugars plus starch) ${ }^{14}$. Mean protein intakes were lower for the Pakistani men than for the other men and higher for the European women than for the other women. BMI for the European men was higher than for the other two groups; among women, Pakistanis had the highest BMI, followed by the African-Caribbean women and the European women (Table 1). The percentage of energy from fat was highest in the subjects of Pakistani origin.

\section{Quintile analysis}

Analysis by quintiles of nutrient intake showed a significant increase in circulating IGF-I concentration with increasing dietary fat intake $(F=3.9, P=0.005)$ (Fig. 1). This relationship held when the analysis was carried for each ethnic group separately (Fig. 2). For the groups combined there was an increase in IGF-I by quintiles of saturated fat intake $(F=3.3, P=0.01)$ (Fig. 3a) and protein intake $(F=4.2, \quad P=0.003)$ (Fig. 3b). There was also a significant increase in IGF-II by quintiles of dietary protein intake $(F=2.7, P=0.02)$ (Fig. 3c). There was a trend for increase in IGF-I by total energy intake $(F=2.2, P=0.06)$ (data not shown).

\section{Pearson correlations (Table 2) and interetbnic variation of IGFs}

\section{$I G F-I$}

For the group as a whole, IGF-I correlated positively with total fat and saturated fat intakes and with protein intake. In men IGF-I correlated positively with percentage energy from saturated fat $(r=0.26, P=0.009)$. IGF-I correlated 


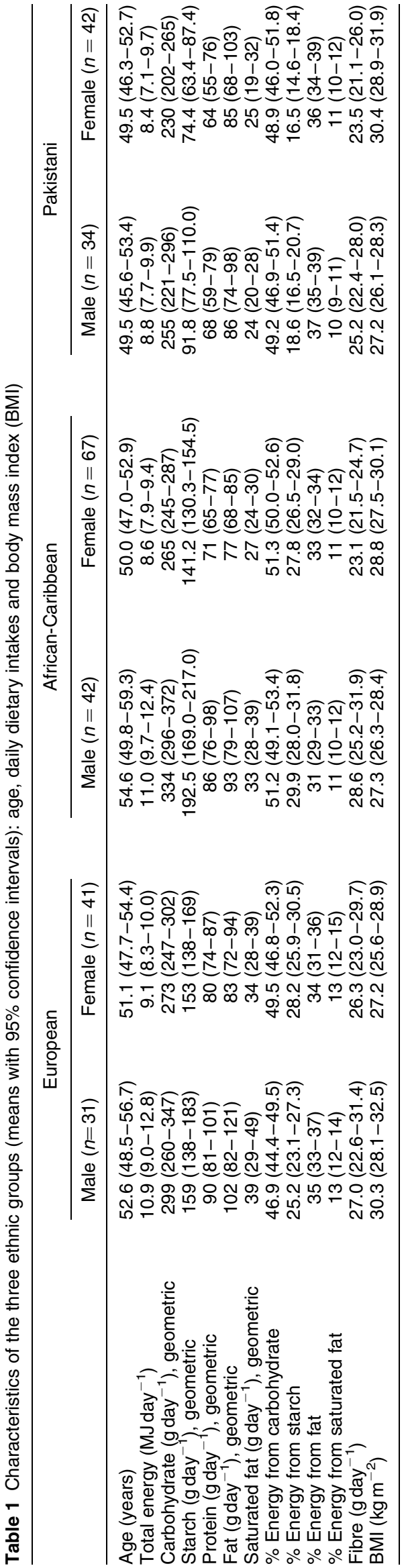

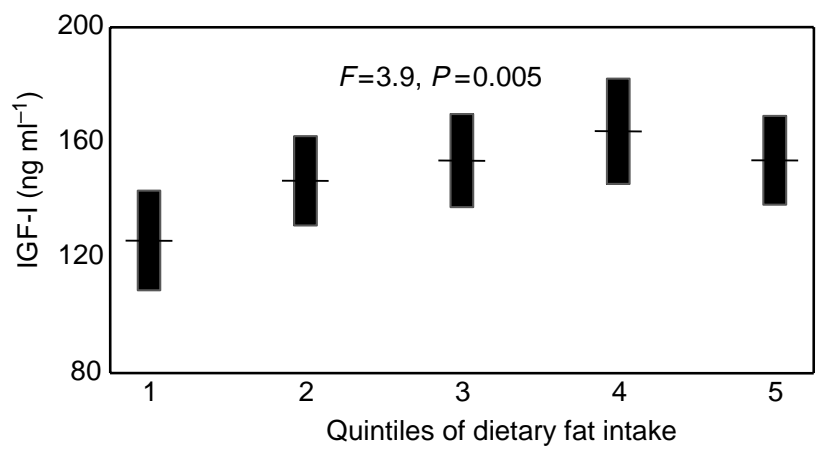

Fig. 1 Serum concentrations of insulin-like growth factor-I (IGF-I) plotted against quintiles of total fat intake for all ethnic groups combined (arithmetic means with 95\% confidence intervals)

positively with carbohydrate and starch intakes and with total energy intake. After adjustment for age and sex, IGF-I was significantly higher in African-Caribbeans than in Europeans or Pakistanis ${ }^{13}$.
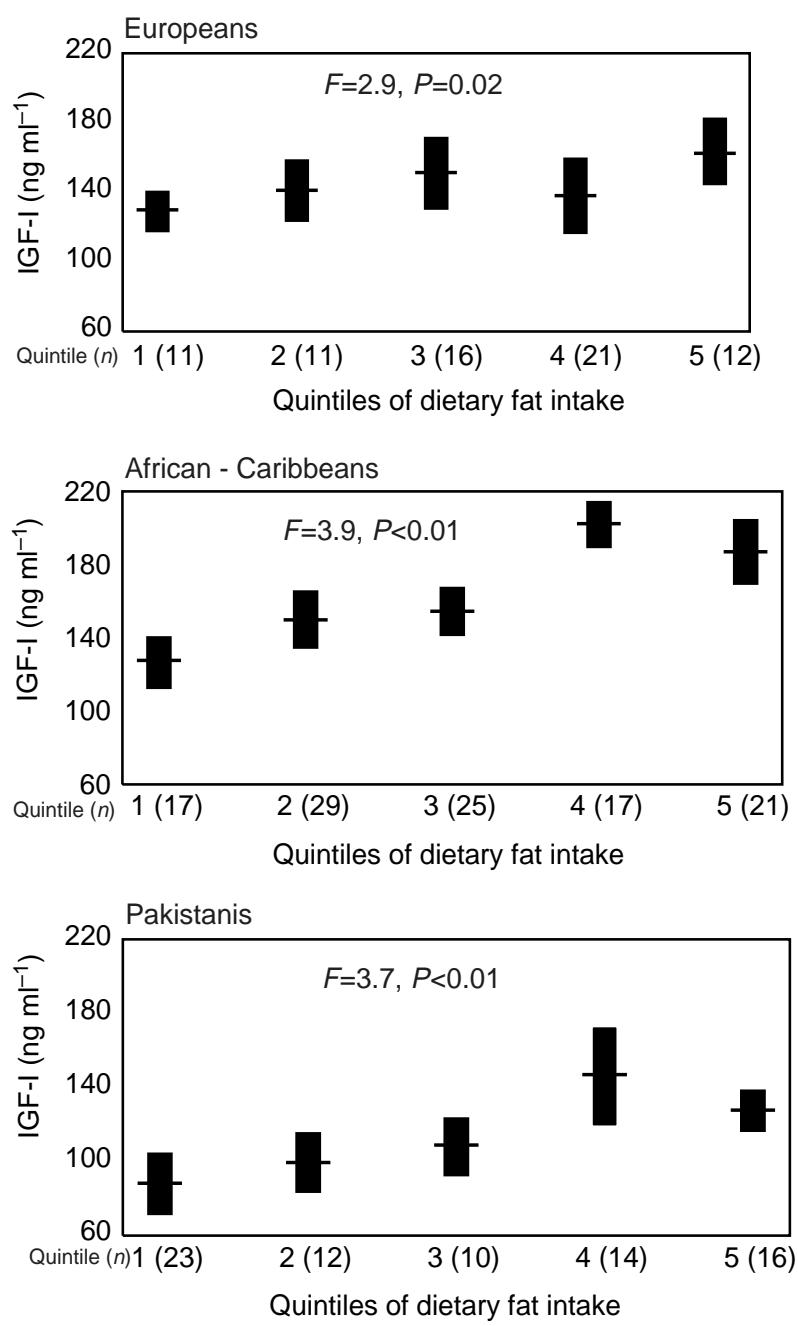

Fig. 2 Serum concentrations of insulin-like growth factor-I (IGF-I) plotted against quintiles of total fat intake for each ethnic group (arithmetic means with standard error of the mean) 


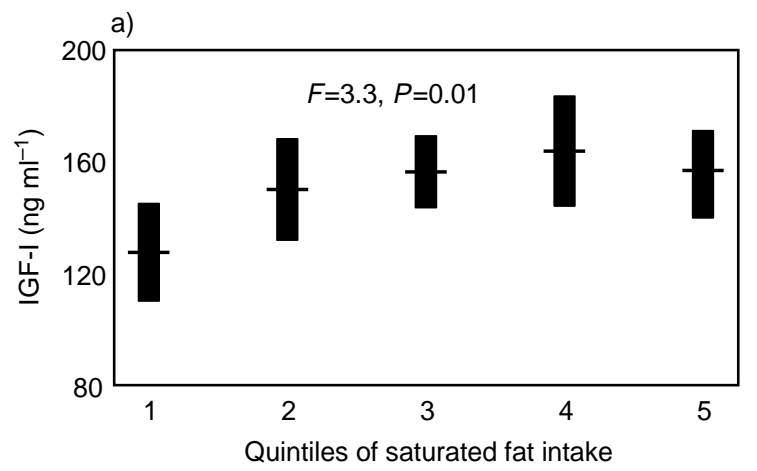

b)

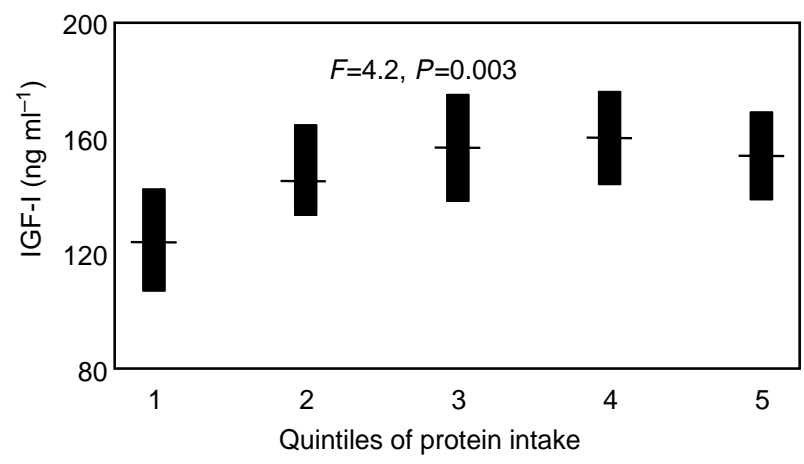

c)

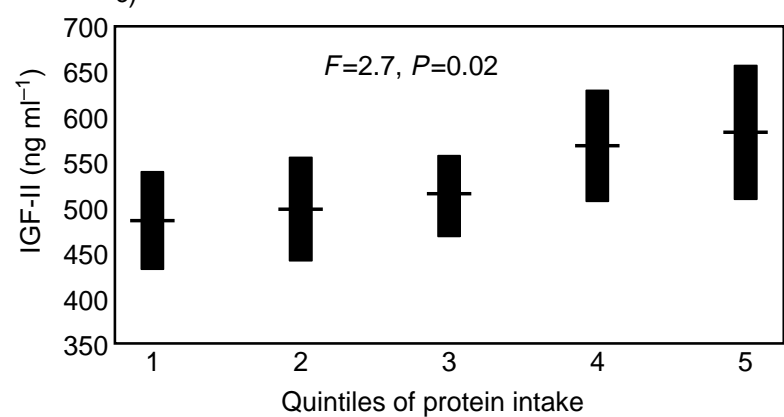

Fig. 3 Serum concentrations of insulin-like growth factor-I (IGF-I) by: (a) quintiles of saturated fat intake for all ethnic groups combined (arithmetic means with 95\% confidence intervals) and (b) quintiles of protein intake for all ethnic groups combined (arithmetic means with $95 \%$ confidence intervals). (c) Serum concentrations of insulin-like growth factor-II (IGF-II) by quintiles of protein intake for all ethnic groups combined (arithmetic means with $95 \%$ confidence intervals)

\section{$I G F-I I$}

IGF-II correlated positively with total protein intake and with iron intake (both markers for red meat intake). There was a trend for IGF-II to be associated with saturated fat intake ( $r=0.14, P=0.06$ ). When analysis was carried out for fat intake in the gender groups separately, IGF-II correlated with percentage energy from saturated fat in men $(r=0.21, P=0.03)$, with the strongest relationship between IGF-II and total fat intake being in European men $(r=0.38, P=0.04)$. For males dietary total fat intake was highest in this group (Table 2 ) as was dietary saturated fat intake. In contrast to IGF-I but in keeping with the data on fat intake, the IGF-II concentration was markedly elevated in Europeans compared with African-Caribbeans and Pakistanis $^{13}$.

IGFBP-1

IGFBP-1, which acts as an acute inhibitor of IGF action, correlated negatively with total fat and polyunsaturated fat (PUFA) intakes and also with total protein intake. Conversely, the ratio of IGF-I/IGFBP-1, a surrogate measure of IGF bioavailability, correlated positively with total fat and PUFA intakes and with total protein intake (Table 2).

\section{Multiple linear regression modelling}

A dominant effect of ethnicity and age on IGF-I levels was demonstrated using a multiple linear regression model that also included gender, BMI, fasting insulin, and total fat, protein and carbohydrate intakes. Since IGF-I was logtransformed, the anti-log of the unstandardised beta coefficient can be interpreted as the percentage change in IGF-1 compared with a one-unit change in nontransformed independent variables. IGF-I was independently and negatively related to Pakistani ethnicity ( $\beta=-0.26, \quad P<0.001)$, i.e. subjects who were of Pakistani origin had 23\% lower IGF-I than the subjects of European origin. Lower IGF-I was associated with increasing age $(\beta=-0.01, P<0.001)$ so that, for every one year increase in age, IGF-1 decreased by $1 \%$. The nutrients in the model were log-transformed. After adjustment for the other factors in the model a significant inverse association remained with carbohydrate $(\beta=$ $-0.23, P=0.036)$. This can be interpreted as follows: for every one-unit change in the log of carbohydrate, there is a reduction of $21 \%$ in IGF-I. So, for example, for a doubling of carbohydrate in the diet, IGF-I will be $15 \%$ lower. There was no independent relationship between IGF-I and either protein or fat.

In a multiple linear regression model that included age, gender, BMI, fasting insulin, percentage energy from fat, carbohydrate and protein and total energy intakes, we found that ethnic group and age were still strongly associated with circulating IGF-I but the effect of carbohydrate intake on IGF-I levels was no longer apparent.

Table 2 Pearson correlations $(r)$ of insulin-like growth factor (IGF)-I, IGF-II and IGF-binding protein-1 (IGFBP-1) with nutrient intake for the whole group

\begin{tabular}{lcccc}
\hline Nutrient & IGF-I & IGF-II & $\begin{array}{c}\text { Log } \\
\text { (IGFBP-1) }\end{array}$ & $\begin{array}{c}\text { Log } \\
\text { (IGF-I/IGFBP-1) }\end{array}$ \\
\hline Total fat & $0.14^{\star}$ & 0.14 & $-0.16^{\star}$ & $0.16^{\star}$ \\
Saturated fat & $0.15^{\star \star}$ & 0.14 & -0.12 & 0.12 \\
Polyunsaturated fat & -0.05 & 0.11 & $-0.15^{\star}$ & $0.16^{\star}$ \\
Protein & $0.16^{\star \star}$ & $0.18^{\star}$ & $-0.16^{\star}$ & $0.17^{\star}$ \\
Iron & -0.03 & $0.16^{\star}$ & -0.12 & 0.11 \\
Carbohydrate & $0.12^{\star}$ & 0.12 & -0.09 & $0.13^{\star}$ \\
Starch & $0.24^{\star \star}$ & 0.07 & -0.08 & $0.16^{\star \star}$ \\
Total energy & $0.17^{\star *}$ & 0.12 & -0.09 & $0.13^{\star}$ \\
\hline
\end{tabular}

*, Two-tailed $P<0.05 ;{ }^{* *}$, two-tailed $P<0.01$. 


\section{Discussion}

This study provides evidence for dietary regulation of the IGF system, in the context of significant differences in IGF levels between ethnic groups. Increased IGF-I is linked with a lower carbohydrate intake. IGF-I and IGF-II concentrations correlate with higher protein intake. There are independent negative correlations of fat and protein intake with circulating IGFBP-1 concentrations. The exact nature of the relationships between food intake and levels of IGFs in the circulation remains to be determined. While dietary factors appear here to influence the IGF system less than ethnicity per se, and only carbohydrate was significant in a full regression model, we have demonstrated a relationship between dietary fat intake within individual groups.

In the linear regression model there was a high degree of collinearity between protein, fat and carbohydrate, making distinction between the effect of each less clear. This is illustrated by the fact that in a univariate analysis carbohydrate was positively associated with IGF-I. However, in the regression model adjusting for other energy-containing nutrients, the direction of the relationship between carbohydrate and IGF-I was reversed. Also, the fact that dietary variables of fat and protein intake were not independently associated with IGF-I to a significant degree in the full regression model may reflect difficulties in characterising the cumulative impact of dietary intake over time on single estimates of circulating IGF and IGFBP-1 levels.

Correlations between dietary carbohydrate, fat and protein and IGF-I in healthy individuals of individual ethnic groups have been described previously ${ }^{15,16}$. Our results are consistent with the negative association found between carbohydrate and IGF-I by Kaklamani et al. ${ }^{15}$. The biological basis for this finding is suggested as being related to the positive regulation of IGF-I levels by growth hormone $(\mathrm{GH})$, which is in turn regulated by postprandial hyper- or hypoglycaemia. Although we did not have specific data on animal protein intake, a recent study has shown that vegan men had circulating IGF-I levels $9 \%$ lower on average than those of meat eaters, with adjustment for BMI making little difference to these values $^{17}$. Animal models have been developed to investigate the mechanisms that are responsible for the nutritional regulation of IGF-I $^{18}$. There is no doubt that many mechanisms are involved. The decrease in serum IGF-I with dietary restriction is independent of dietinduced alterations in pituitary GH restriction. The role of the liver GH receptors is dependent on the severity of the nutritional insult. In severe dietary restriction with fasting, there is a marked decrease in the number of GH receptors. In contrast, in less severe forms of dietary restriction (protein restriction), the decline in IGF-I results from a post-receptor defect in GH action at the hepatic level. Diet restriction also increases the clearance and degradation of circulating IGF-I through changes in the levels of circulating IGFBPs.

The finding of potential dietary regulation of IGF-II is novel and the fact that IGFBP-1, the principal hour-to-hour modulator of IGF bioavailability ${ }^{19}$, tends to be lowered by the dietary factors that increase total IGF levels could further enhance IGF action at the tissue level.

The association that we have found in humans between IGF-I and total energy intake accords with previous studies $^{20}$. Experiments on animals have shown that energy restriction can reduce the risk of cancer and inhibit tumour growth $^{21,22}$ and that this effect can be attributed in part to the IGFs ${ }^{23,24}$. Restriction of energy intake in rats transplanted with human prostate cells slows the growth of cancer and accelerates apoptosis ${ }^{23}$. These effects are associated with a decrease in circulating IGF-I. Furthermore, the beneficial effects of dietary restriction on reducing the growth rate of bladder cancer in mice are abrogated upon administration of IGF-I ${ }^{24}$. This suggests that the effect of energy restriction on cancer may be mediated mainly through IGF-I.

Although this study has demonstrated an association of total energy and dietary factors on the IGF system, the exact nature of the dose-response relationships between food intake and levels of IGFs in the circulation remains to be determined and is limited by the imprecision of the dietary measures currently available. We have previously reported the effects of ethnic variation on circulating IGF-I, IGF-II and IGFBP-1 levels ${ }^{13}$. While the influence of dietary factors on the IGF system appears less than that of ethnicity, this may reflect the difficulties in assessing the cumulative impact of dietary intake over time on circulating IGF and IGFBP-1 levels. We accept that a measurement error may result from the use of ethnicgroup-specific questionnaires. It was not possible to adjust for this in our analysis.

The importance of non-genomic factors in the development of cancers has recently been highlighted ${ }^{25}$. Evidence suggests that lifestyles characterised by a highenergy diet may affect the IGF system and predispose cells to a higher risk of malignant transformation. We propose that the differences between ethnic groups in levels of IGF-I and IGF-II are not completely explained by macronutrient intake and that there is significant genetic influence in determining circulating levels of the IGFs. However, differences in IGF levels within ethnic groups may still be modifiable by dietary intervention. This has important preventive and therapeutic implications for managing disease risk within the population in the future.

\section{Acknowledgements}

This work was funded by the Ministry of Agriculture, Fisheries and Food, Project No. GE 213 CYP, and the North West Research and Development Directorate, Project No. RDO/22/4. 


\section{References}

1 Department of Health. Saving Lives: Our Healthier Nation. London: The Stationery Office, 1999.

2 Davey Smith G, Gunnell D, Holly J. Cancer and insulin-like growth factor-I. Br. Med.J. 2000; 321: 847-8.

3 Jones JI, Clemmons DR. Insulin-like growth factors and their binding proteins: biological actions. Endocr. Rev. 1995; 16: 3-34.

4 Hankinson SE, Willett WC, Colditz GA, Hunter DJ, Michaud DS, Deroo B, et al. Circulating concentrations of insulin-like growth factor-I and risk of breast cancer. Lancet 1998; 351: 1393-6.

5 Chan JM, Stampfer MJ, Giovannucci E, Gann PH, Ma J, Wilkinson P, et al. Plasma insulin-like growth factor-I and prostate cancer risk: a prospective study. Science 1998; 279: 563-6.

6 Ma J, Pollak MN, Giovannucci E, Chan JM, Tao Y, Hennekens $\mathrm{CH}$. Prospective study of colorectal cancer risk in men and plasma levels of insulin-like growth factor (IGF)-I and IGFbinding protein-3. J. Natl. Cancer Inst. 1999; 91: 620-5.

7 Spallarossa P, Brunelli C, Minuto F, Caruso D, Battistini M, Caponnetto $\mathrm{S}$, et al. Insulin-growth factor-I and angiographically documented coronary heart disease. Am. J. Cardiol. 1996; 77: 200-2.

8 Toretsky JA, Helman LJ. Involvement of IGF-II in human cancer. J. Endocrinol. 1996; 149: 367-72.

$9 \mathrm{Yu} \mathrm{H}$, Rohan T. Role of the insulin-like growth factor family in cancer development and progression. J. Natl. Cancer Inst. 2000; 92: 1472-89.

10 Sharma S, Cade J, Jackson M, Mbanya JC, Chungong S, Forrester T, et al. Cross cultural assessment of diet in three population samples of African origin from Cameroon, Jamaica and Caribbean migrants to the UK: method development. Eur. J. Clin. Nutr. 1996; 50: 479-86.

11 Crawley H. Food Portion Sizes. London: Ministry of Agriculture, Fisheries and Food/Her Majesty's Stationery Office, 1988

12 Heald AH, Cruickshank JK, Riste LK, Cade JE, Anderson S, Greenhalgh A, et al. Close relationship of fasting insulin-like growth factor binding protein-1 (IGFBP-1) with glucose tolerance and cardiovascular risk in 2 populations. Diabetologia 2001; 44: 333-9.

13 Cruickshank JK, Heald AH, Anderson S, Cade J, Sampayo J, Riste LK, et al. Epidemiology of the insulin-like growth factor system in three ethnic groups. Am. J. Epidemiol. 2001; 154: $504-13$.
14 Asp NG. Carbohydrates - terminology update. Carbobydrates 2000; 11: $1-3$.

15 Kaklamani VG, Linos A, Kaklamani E, Markaki I, Koumantaki Y, Mantzaros CS. Dietary fat and carbohydrates are independently associated with circulating insulin-like growth factor-I and insulin-like growth factor binding protein-3 concentrations in healthy adults. J. Clin. Oncol. 1999; 17: 3291-8.

16 Devine A, Rosen C, Mohan S, Baylink D, Prince RL. Effects of zinc and other nutritional factors on insulin-like growth factor-I and insulin-like growth factor binding proteins in healthy post-menopausal women. Am. J. Clin. Nutr. 1998; 68: $200-6$.

17 Allen NE, Appleby PN, Davey GK, Key TJ. Hormones and diet: low insulin-like growth factor-I but normal biochemical androgens in vegan men. Br.J. Cancer 2000; 80: 95-7.

18 Thissen JP, Ketelslegers JM, Underwood LE. Nutritional of the insulin-like growth factors. Endocr. Rev. 1994; 15: 80-101.

19 Lee PD, Giudice LC, Conover CA, Powell DR. Insulin-like growth factor binding protein-1: recent findings and new directions. Proc. Soc. Exp. Biol. Med. 1997; 216: 319-57.

20 Clemmons DR, Klibanski A, Underwood LE, McArthur JW, Ridgway EC, Beitins IZ, et al. Reduction of plasma immunoreactive somatomedin $\mathrm{C}$ during fasting in humans. J. Clin. Endocrinol. Metab. 1981; 53: 1247-50.

21 Cohen LA, Choi KW, Wang CX. Influence of dietary fat, calorie restriction and voluntary exercise on $\mathrm{N}$-nitrosomethylureainduced tumourigenesis in rats. Cancer Res. 1988; 48 4276-83.

22 Hursting SD, Perkins SN, Phang JM. Calorie restriction delays spontaneous tumourigenesis in p53-knockout transgenic mice. Proc. Natl. Acad. Sci. USA 1994; 91: 7036-40.

23 Mukherjee P, Sotnikov AV, Mangian HJ, Zhou JR, Visek WJ, Clinton SK. Energy intake and prostate tumour growth, angiogenesis and vascular endothelial growth factor expression. J. Natl. Cancer Inst. 1999; 91: 512-23.

24 Dunn SE, Kari FW, French J, Leininger JR, Travlos J, Wilson R, et al. Dietary restriction reduces insulin-like growth factor-I levels which modulates apoptosis, cell proliferation and tumour progression in p53-defidient mice. Cancer Res. 1997; 57: 4667-72.

25 Lichtenstein P, Holm NV, Verkasalo PK, Iliadou A, Kaprio J, Koskenvuo M, et al. Environmental and heritable factors in the causation of cancer - analyses of cohorts of twins from Sweden, Denmark and Finland. N. Engl. J. Med. 2000; 343 $78-85$. 